\title{
AVALIAÇÃO DO TRABALHO DA EQUIPE TÉCNICO-PEDAGÓGICA DA DIRETORIA DE GESTÃO E TECNOLOGIA DA INFORMAÇÃO DO CAMPUS NATAL-CENTRAL DO IFRN: DESAFIOS E PERSPECTIVAS
}

\author{
É. L. G. T. GOMES ${ }^{1 *}$, G. L. PAIVA ${ }^{2}$ e L. T. S. GARCIA ${ }^{2}$ \\ ${ }^{1}$ Instituto Federal de Educação, Ciência e Tecnologia do Rio Grande do Norte \\ ${ }^{2}$ Universidade Federal do Rio Grande do Norte \\ erica.torres@ifrn.edu.br*
}

Artigo submetido em abril/2016 e aceito em setembro/2016

DOI: $10.15628 /$ holos.2016.4372

\section{RESUMO}

Este artigo analisa o processo de avaliação do trabalho da Equipe Técnico-Pedagógica (ETEP) da Diretoria de Gestão e Tecnologia da Informação (DIATINF), desenvolvido em 2013, como uma ação piloto para a implementação da avaliação institucional no Instituto Federal de Educação, Ciência e Tecnologia do Rio Grande do Norte, Campus Natal-Central (IFRN/CNAT). Trata-se de uma pesquisa qualitativa, que tomou como procedimentos a revisão bibliográfica, a análise documental e aplicação de questionários com professores e estudantes. Os resultados obtidos consideram as fragilidades $\mathrm{e}$ potencialidades do trabalho da ETEP, destacando as contribuições da avaliação para a melhoria da qualidade desse trabalho.

PALAVRAS-CHAVE: Avaliação institucional, Equipe técnico-pedagógica, IFRN.

\section{THE EVALUATION OF THE WORK OF TECHNICAL-PEDAGOGICAL TEAM OF THE DIRECTORY OF MANAGEMENT AND INFORMATION TECHNOLOGY - CAMPUS NATAL/CENTRAL - IFRN: CHALLENGES AND PROSPECTS}

\section{ABSTRACT}

This article analyses the process of evaluation of the work of the Technical-Pedagogical Team (ETEP) of the directory of Management and Information Technology (DIATINF), developed in 2013 as a pilot action for the implementation of institutional assessment at the Federal Institute of Education, Science and Technology of Rio Grande do Norte - Campus Natal/Central (IFRN/
\end{abstract}

CNAT). This qualitative research took as procedures: the literature review, documents analysis and questionnaires with teachers and students. The results consider the fragilities and capabilities of ETEP's work, highlighting the contributions of the evaluation to improving the quality of that work.

KEYWORDS: Institutional assessment, Technical-pedagogical team, IFRN. 


\section{INTRODUÇÃO,}

Ainda hoje, usualmente, ao ouvir falar sobre avaliação escolar, as pessoas pensam em classificação, resultados, punição, culpados, erros. Em grande medida, associam a avaliação a um meio de quantificar o grau da aprendizagem dos sujeitos, utilizando-se de índices numéricos para classificá-los como aptos ou inaptos. No entanto, crescem, em número, as experiências de avaliações formativas que objetivam a coleta de dados da realidade visando a subsidiar a melhoria dos processos educativos. Esses dados orientam os processos decisórios, necessários para que sejam alcançados determinados fins, quer seja no que se refere à gestão da aprendizagem quer seja das instituições.

A avaliação das instituições assumiu centralidade, nas atuais políticas educacionais, e é realizada por agentes externos por meio da participação dos estudantes em sistemas nacionais de avaliação que incidem sobre todos os níveis educacionais. As avaliações de sistemas, supostamente, possuem o intuito de subsidiar a melhoria da qualidade educacional. Assemelham-se, no entanto, a práticas de controle dos resultados obtidos pelas instituições e de responsabilização dos profissionais, sem que as reais condições de melhoria do trabalho educativo sejam conferidas pelo poder público.

A despeito de as instituições públicas serem avaliadas externamente, a vivência da gestão democrática demanda que, no exercício de sua autonomia relativa, estas empreendam processos de planejamento, implementação e avaliação coletiva do trabalho desenvolvido, visando ao alcance de resultados. Cada um desses processos demanda avaliações contínuas que exigem ajustes no curso das ações.

A avaliação institucional interna, ou seja, a avaliação do trabalho realizado pelos próprios sujeitos interessados em sua melhoria, na concepção de Fernandes (2002), constitui-se em instrumento para sua transformação e aperfeiçoamento, visto que possibilita identificar dificuldades e sucessos, capazes de superar e consolidar experiências que colaborem para a construção da qualidade e da democratização escolar. Nesse sentido, Freitas et al. (2009, p. 35) consideram que a "[...] avaliação institucional da escola é um processo que envolve todos os seus atores, com vistas a negociar patamares de aprimoramento, a partir dos problemas concretos vivenciados por ela".

Visando à melhoria da qualidade do seu trabalho educativo, o Instituto Federal de Educação Ciência e Tecnologia do Rio Grande do Norte (IFRN) define, em seu Projeto PolíticoPedagógico, que a "[...] avaliação é um instrumento fundamental para todo organismo social que busque desenvolvimento e qualidade na busca da democratização do saber" (PPP-IFRN, 2012, p.267). Nesse sentido, a avaliação no IFRN é dividida em: avaliação institucional; avaliação de cursos; avaliação do desempenho do estudante; avaliação de servidores; e avaliação de programas.

Pertinente à avaliação institucional, desde 2010, a Equipe Técnico-Pedagógica (ETEP) da Diretoria de Gestão e Tecnologia da Informação (DIATINF) do campus Natal-Central (CNAT) do IFRN vem fomentando discussões sobre a temática. A importância dessa avaliação está expressa 
no PPP da Instituição (IFRN, 2012) que a relaciona à melhoria do trabalho desenvolvido, tendo por finalidade identificar o andamento e a qualidade das atividades-fim (ensino, pesquisa e extensão) e das atividades-meio (gestão acadêmica e administrativa) que devem ocorrer com a participação da comunidade acadêmica.

Apesar da sua amplitude, o processo de avaliação institucional proposto no ano de 2013 pela DIATINF, no âmbito do acompanhamento do processo de ensino-aprendizagem, previa a construção e a aplicação de instrumentos de autoavaliação para os discentes, a análise das turmas realizada pelo aluno e pelo professor e os docentes, que tinham sua prática avaliada por seus alunos. Dessa forma, não estava prevista a verificação do trabalho desenvolvido pelos servidores em geral, particularmente, os pedagogos que acompanham o trabalho pedagógicoadministrativo na instituição.

Considerando que a avaliação institucional deve envolver toda a comunidade escolar, a ETEP/DIATINF sentiu a necessidade de avaliar, também, o seu trabalho. Por isso, mesmo que essa prática não integrasse, a princípio, a avaliação interna da instituição, a ETEP/DIATINF desenvolveu instrumentos para que alunos e professores/gestores dessa diretoria analisassem também o seu trabalho. A proposta de avaliar a equipe da diretoria foi vista, inicialmente, com surpresa pelos professores e alunos, que, até então, não haviam tido essa oportunidade. Além de analisar a experiência de avaliação desenvolvida pela referida equipe técnica, este artigo demonstra a importância dessa prática para a melhoria da qualidade do trabalho educativo, desenvolvido na instituição.

\section{METODOLOGIA}

Compreendendo a importância da avaliação institucional para a construção da qualidade do trabalho educativo, este artigo objetiva analisar o processo de avaliação do trabalho da Equipe Técnico-Pedagógica (ETEP), da Diretoria de Gestão e Tecnologia da Informação (DIATINF), realizado, de forma piloto, no Instituto Federal de Educação, Ciência e Tecnologia do Rio Grande do Norte (IFRN). Abordar-se-á, especificamente, a proposta de avaliação da ETEP e suas contribuições para a melhoria do trabalho desenvolvido. Para tanto, leva-se a efeito o princípio da globalidade, que, de acordo com Ristoff (2008, p. 41), “[...] expressa, primeiramente, a noção de que é necessário avaliarmos a instituição não só a partir de uma de suas atividades". Para o autor, o ensino, a pesquisa, a extensão, a administração, a estrutura física, a biblioteca, os serviços e os demais aspectos que compõem a vida escolar devem fazer parte da avaliação. Dessa forma, será analisado o processo empreendido em sua totalidade, considerando a análise do trabalho da equipe como um todo.

Este trabalho consiste em uma pesquisa aplicada, associada à prática desenvolvida na DIATINF, Campus Natal-Central do IFRN. Quanto à forma de abordagem do problema, constituise em uma pesquisa qualitativa, portanto, parte da descrição da realidade, analisando os dados, com foco no processo e seus significados.

Como procedimentos de pesquisa, foram desenvolvidos revisão da literatura, análise documental e aplicação de questionários. Levar-se-á a efeito a análise bibliográfica com o 
objetivo de compreender a avaliação institucional e o papel que o coordenador pedagógico desempenha na instituição escolar. Entre outros documentos, foi analisado o Projeto PolíticoPedagógico do IFRN (IFRN, 2012) e o Ofício Circular no 15 (BRASIL, 2005) que descreve os cargos técnico-administrativos na área da educação.

Ademais, foram analisamos dados coletados por meio de questionário enviado para os 55 docentes e 430 alunos do Curso Técnico de Nível Médio Integrado. A pesquisa foi desenvolvida com professores e estudantes do ensino médio, porque a ETEP faz um acompanhamento mais próximo com as pessoas que atuam nessa etapa da escolaridade. A taxa de resposta aos questionários constituiu uma amostra de $44 \%$ dos alunos e $23 \%$ professores da DIATINF. Segundo Levin (1987), uma significativa amostra deve estar entre 20 a 30\% do universo da pesquisa, de forma que, nesta pesquisa, esses números foram superados.

Além da introdução e do desenvolvimento metodológico, este artigo compõe-se de mais três itens, nos quais caracteriza-se, brevemente, a instituição onde a pesquisa ocorreu e o trabalho da ETEP/DIATINF; analisa-se a proposta de avaliação empreendida bem como os resultados obtidos, e finalmente, apresentam-se as nossas considerações finais.

\section{CONTEXTUALIZANDO O TRABALHO REALIZADO PELA ETEP DA DIATINF NO IFRN CAMPUS CENTRAL}

Conforme o projeto político-pedagógico do Instituto Federal de Educação, Ciência e Tecnologia do Rio Grande do Norte (IFRN, 2012), esta é uma instituição de educação superior, básica e profissional, especializada na oferta de educação profissional e tecnológica em diferentes modalidades de ensino. Para tanto, busca conjugar conhecimentos científicos, técnicos e tecnológicos a ideais pedagógicos de fundamentação histórico-crítica (IFRN, 2012).

No Rio Grande do Norte, o IFRN conta com 19 campi em funcionamento, com organização pluricurricular visando oferecer ensino público, laico, gratuito e de qualidade à população. Oferta cursos em sintonia com sua função social de

[...] ofertar educação profissional e tecnológica - de qualidade referenciada socialmente e de arquitetura político-pedagógica capaz de articular ciência, trabalho, cultura e tecnologia - comprometida com a formação humana integral, com o exercício da cidadania e com a produção do conhecimento e a socialização do conhecimento, visando, sobretudo, a transformação da realidade na perspectiva da igualdade e da justiça sociais (IFRN, 2012, p. 26).

Nesse sentido, o seu currículo é organizado com base em quatro eixos: ciência, trabalho, cultura e tecnologia, articulados entre si como princípios norteadores da prática educativa. $\mathrm{O}$ Instituto desenvolve pesquisa e extensão, na perspectiva da produção, socialização e difusão de conhecimentos. Estimula a produção cultural e realiza processos pedagógicos que colaborem para a geração de trabalho e de renda para a população, visando consolidar e fortalecer arranjos produtivos, culturais e sociais locais. Em uma perspectiva mais ampla, tem como intento contribuir para as transformações sociais, por meio dos processos educacionais desenvolvidos, tomando as relações sociais como ponto de partida do seu trabalho. 
O Campus Natal-Central (CNAT) do IFRN está situado na Av. Senador Salgado Filho, 1159, Bairro Tirol, Natal/RN. Numa área de $90.000 \mathrm{~m}^{2}$, o campus é dividido em estrutura administrativa, acadêmica e esportiva com amplas instalações necessárias ao desenvolvimento da sua função social. As atividades e ofertas institucionais se organizam por área de conhecimento e profissionais. Dessa forma, o campus possui cinco Diretorias Acadêmicas: Diretoria de Ciências (DIAC); Diretoria de Construção Civil (DIACON); Diretoria de Gestão e Tecnologia da Informação (DIATINF); Diretoria de Indústria (DIACIN) e Diretoria de Recursos Naturais (DIAREN).

A Diretoria Acadêmica de Gestão e Tecnologia da Informação (DIATINF) dispõe de uma equipe composta por dois Técnico-administrativos de nível superior (pedagogas), cinco técnico- administrativos de nível médio (Secretários acadêmicos), dois técnicos de laboratório, aproximadamente sessenta docentes, entre efetivos e substitutos, além de cerca de dez estagiários e bolsistas. A diretoria oferta cursos Técnicos de Nível Médio Integrado às áreas de Administração, Informática para Internet assim como Manutenção e Suporte em Informática. Os Cursos Superiores de Tecnologia de Análise e Desenvolvimento de Sistemas, Comércio Exterior, Gestão Pública, Redes de Computadores também estão sob a responsabilidade da DIATINF, que fomenta o desenvolvimento de ações de pesquisa e extensão, envolvendo docentes, discentes, parcerias com o setor produtivo e com outras instituições nessas áreas.

A Equipe Técnico-Pedagógica (ETEP) do IFRN é uma equipe composta por dois tipos de profissionais: Técnico-Administrativos de Nível Superior - Pedagogo e Técnico-Administrativo de Nível Superior - Técnico em Assuntos Educacionais, podendo este, como requisito de qualificação para ingresso no cargo, possuir curso superior em Pedagogia ou outras Licenciaturas.

As práticas desenvolvidas pela ETEP no IFRN constam em um documento (IFRN, 2009), elaborado, em 2009, pela própria equipe com a participação da Diretoria Pedagógica/PROEN e anuência da então Pró-Reitoria de Ensino. Este documento tomou como base o Ofício Circular no 15 (BRASIL, 2005), de abrangência nacional, que descreve os cargos técnico-administrativos em educação, autorizados para concurso público pelo Ministério de Planejamento, Orçamento e Gestão.

Conforme o documento (IFRN, 2009), o trabalho da Equipe Técnico-Pedagógica, nas diretorias acadêmicas do IFRN, deve acontecer junto aos pais/responsáveis, alunos e professores, diretores acadêmicos e coordenadores de cursos em exercício. A equipe tem por objetivo coordenar e sistematizar as atividades de acompanhamento e avaliação do processo ensino-aprendizagem, por meio de atividades de acompanhamento da frequência e do rendimento dos alunos; coordenação e participação no planejamento e realização de reuniões (pedagógicas, de grupos, de pais/responsáveis, conselhos de classe, colegiados de cursos, etc.); identificação e encaminhamento de demandas relacionadas ao trabalho de sala de aula e demais necessidades do currículo; mediação de conflitos e dificuldades nas relações aluno-aluno ou professor-aluno; realização de atendimento individualizado aos professores, pais/responsáveis, alunos ou grupos de alunos; entre outras.

Assim, o acompanhamento do ensino-aprendizagem nos cursos coordenados pela DIATINF/IFRN/CNAT, acontece de forma sistemática pela ETEP que, no ano de 2013, era 
composta por duas pedagogas e uma estagiária do Curso de Pedagogia. Cada uma das servidoras trabalha em um turno letivo e fica responsável pelo acompanhamento das turmas e cursos desse turno. Apesar disso, as atividades da equipe são planejadas em conjunto e executadas em consonância com o planejamento geral da instituição, realizado, anteriormente, por todas as ETEPs que compõem as diretorias dos campi. A despeito de realizar um trabalho articulado com outras equipes, a ETEP da DIATINF promoveu, por si só, um processo de avaliação do próprio trabalho, conforme passaremos a analisar.

\section{A CONSTRUÇÃO DA PROPOSTA DE AVALIAÇÃO DO tRABALHO DA ETEP/DIATINF}

Cada vez mais tem crescido o número de experiências avaliativas desenvolvidas por instituições educacionais de diferentes níveis de escolaridade, tendo como foco a melhoria dos serviços oferecidos à comunidade. A avaliação institucional, de acordo com Libâneo (2001), consiste em

[...] função primordial do sistema de organização e gestão dos sistemas escolares e das escolas. Essa avaliação, também chamada de administrativa, visa à obtenção de dados quantitativos e qualitativos sobre os alunos, os professores, a estrutura organizacional, os recursos físicos e materiais, as práticas de gestão, a produtividade dos cursos e dos professores etc., com o objetivo de emitir juízos valorativos e tomar decisões em relação ao desenvolvimento da instituição (LIBÂNEO, 2001, p. 201).

Nesse sentido, coletam-se dados visando empreender juízos valorativos que subsidiem as tomadas de decisões em relação aos processos e produtos institucionais. Deve-se, portanto, envolver toda a comunidade escolar no desenvolvimento de ações que não possuem finalidades em si mesmas, mas visam à (re)orientação dos processos em curso. É nessa perspectiva que Dias Sobrinho (2008, p. 67) afirma que o "[...] objeto central da avaliação institucional é a qualidade, não só como diagnóstico, mas também como processo de melhoria".

Com esse objetivo, a ETEP/DIATINF se propôs a avaliar o próprio trabalho e, para tanto, inovou em relação aos processos avaliativos que desenvolvia desde 2004 , substituindo os formulários de papel por uma avaliação informatizada. A inovação foi pensada com o intuito de ajustar o tempo de resposta da avaliação ao disponível pelos sujeitos na instituição, não permitir que questões fossem deixadas em branco ou que fossem marcadas mais que uma alternativa, além de possibilitar o arquivamento dos dados por tempo indeterminado. Era necessária a otimização do tempo dispensado para a coleta de dados visto que este interferia diretamente naquele disponível para a análise e encaminhamento das ações decorrentes.

A opção por formulários on-line conferiu maior praticidade à elaboração, apresentação das questões e tabulação dos dados. O caráter autoexplicativo das questões simplificou a aplicação dos questionários assim como a automatização do processo facilitou a organização dos dados e a apresentação das respostas. A plataforma utilizada para a confecção dos formulários, foi o Google Drive, que apresenta design e estilos de perguntas pré-construídas. As figuras 1 e 2 
consistem na captura de imagem dos trechos iniciais dos formulários de avaliação, utilizados com os estudantes e com os professores, respectivamente.

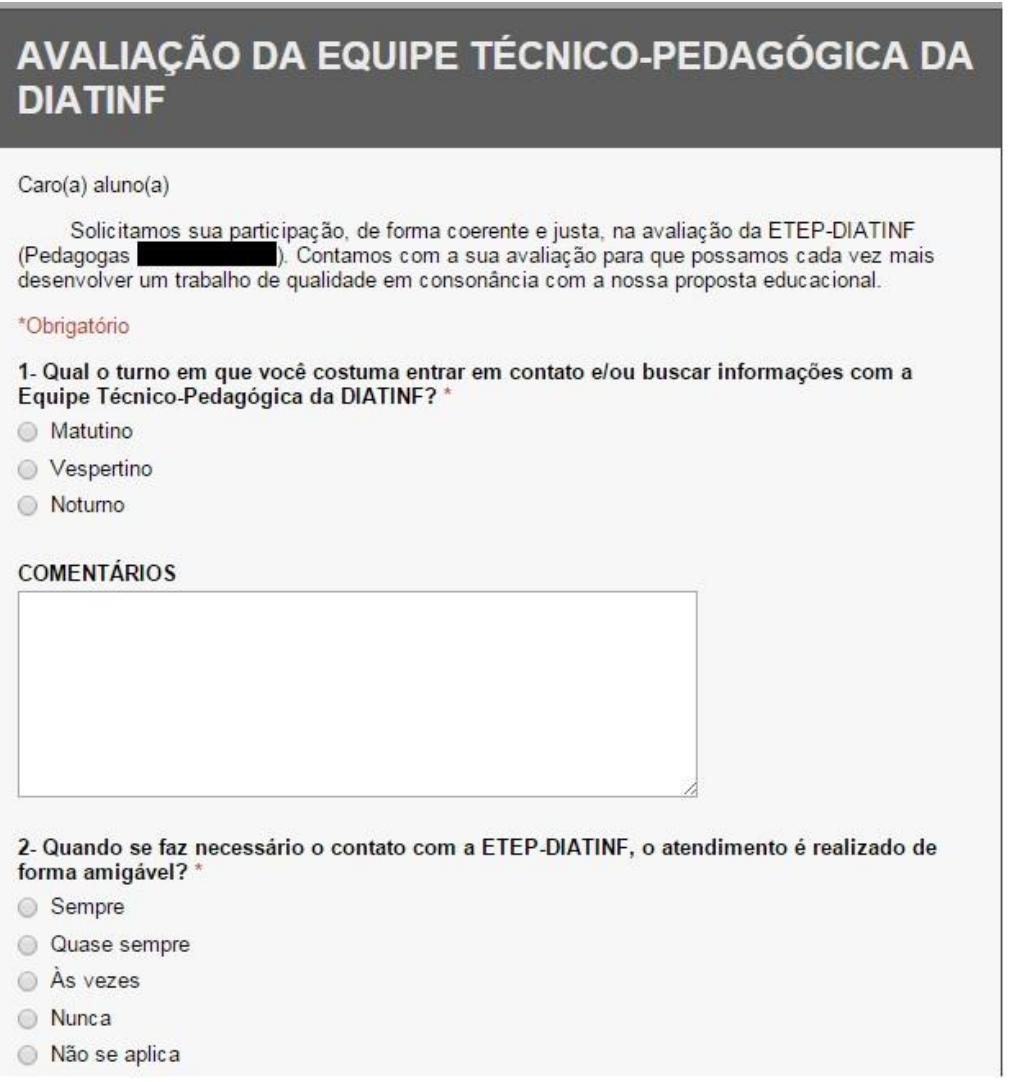

Figura 1: Formulário de avaliação da ETEP DIATINF realizada pelos alunos da DIATINF.

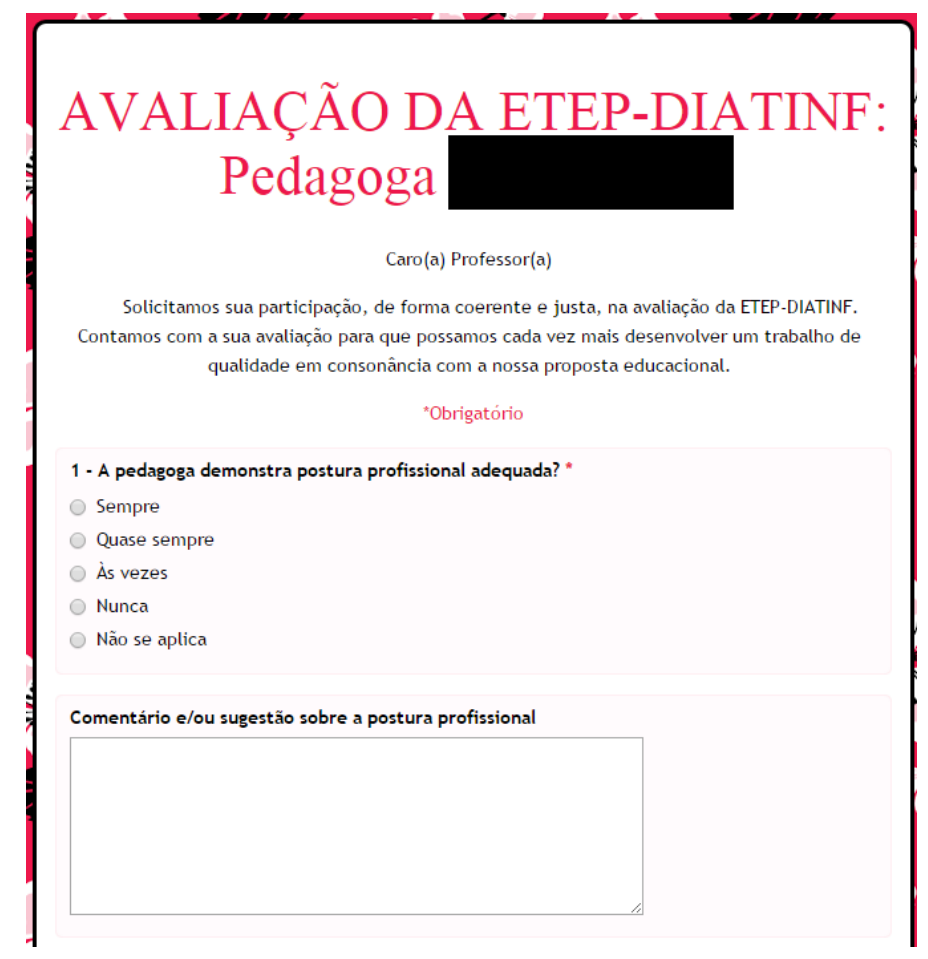

Figura 2: Formulário de avaliação da ETEP DIATINF realizada pelos professores da DIATINF. 
Os formulários foram facilmente compartilhados por e-mail ou por meio de link direto, tornando-se uma opção eficiente e eficaz de coleta de dados. Com o uso de ferramentas eletrônicas, também foi possível acessar planilhas on-line com as respostas submetidas e exportá-las para arquivos do Excel, Open Office ou PDF, para um melhor tratamento dos dados. O formato on-line de aplicação dos questionários, portanto, apresentou vantagens em relação aos formulários de papel utilizados anteriormente, que requeriam maior tempo e trabalho para a tabulação dos dados antes de iniciar a sua análise.

Os itens de avaliação tinham, essencialmente, o intuito de conhecer as percepções dos alunos e professores dessa diretoria a respeito do trabalho realizado pela ETEP, além de averiguar o cumprimento do planejamento desenvolvido por essa equipe. Contudo, tanto os instrumentos utilizados quanto a maneira de operacionalização da aplicação dos questionários foram diferentes para docentes e discentes.

Os dois tipos de formulários abordavam critérios, tais como: pontualidade e assiduidade dos técnicos que atuam no setor; postura profissional; acompanhamento e avaliação do processo ensino-aprendizagem; adequação de prazos para análise e encaminhamento das questões pedagógicas; cumprimento das atribuições previstas para a ETEP, como planejamento e participação nas reuniões de sua responsabilidade, acompanhamento aos alunos, encaminhamento dos educandos para serviços oferecidos pela instituição, mediação de conflitos entre professor- aluno e aluno-aluno, atendimentos individualizados, entre outros aspectos.

A avaliação, nessa perspectiva, tinha como propósito firmar valores. Ristoff (2008, p. 46) nega a sua suposta neutralidade tanto no que se refere à elaboração dos instrumentos quanto a todo o processo que se segue, visto que "[...] são sempre resultado de uma concepção impregnada de valores, sejam eles científico-técnicos, didático-pedagógicos, atitudinais, éticos, políticos ou outro". Havia, por conseguinte, nas perguntas elaboradas pela ETEP, valores desejados ou indesejados em cada uma delas, de forma que as respostas dos sujeitos levariam à análise de se e como os desejados estavam ou não sendo alcançados.

Após cada questão objetiva de múltipla escolha, foi disponibilizado um espaço para que o avaliador deixasse um comentário, uma crítica e/ou uma sugestão, objetivando ter uma visão mais subjetiva do quesito avaliado e uma maior contribuição para a melhoria do trabalho desenvolvido. Isso porque, de acordo com Libânio (2012), considerar, apenas, aspectos quantitativos na avaliação pode não ser suficiente para subsidiar a melhoria do trabalho desenvolvido. Os dados quantitativos precisavam ser analisados à luz da teoria, e as avaliações subjetivas podem auxiliar na compreensão da realidade em questão.

Os estudantes responderam a um questionário único, mas, para os professores, foram elaborados formulários específicos acerca de cada profissional da ETEP, já que as pedagogas atuavam em horários diferentes, atendiam a grupos distintos e possuíam particularidades no atendimento. Apesar de os questionários serem personalizados, essa decisão considerou o princípio da não-punição ou premiação constitutivo da avaliação institucional. Conforme Ristoff (2008, p. 43-44) explica, 
[...] o processo de avaliação não deve estar vinculado a mecanismos de punição ou premiação. Ao contrário, deve prestar-se para auxiliar na identificação e na formulação de políticas, ações e medidas institucionais que impliquem atendimento específico ou subsídios adicionais para o aperfeiçoamento de insuficiências encontradas (RISTOFF, 2008, p. 43-44).

Dessa maneira, objetivou-se criar formulários individuais de avaliação para que os sujeitos avaliados se enxergassem nas avaliações. Isso impulsionaria um processo de autocrítica das pedagogas sobre a própria atuação, que poderia colaborar para repensar objetivos e modos de atuação.

As orientações sobre o preenchimento dos questionários foram passadas aos docentes em uma das Reuniões Pedagógicas (RPs) realizadas, semanalmente, na Diretoria Acadêmica. Os links para acessar os formulários de avaliação foram enviados por e-mail, para que respondessem posteriormente, no horário que lhes fosse conveniente.

O preenchimento do questionário pelos estudantes, no entanto, foi coordenado pela própria ETEP da DIATINF/IFRN/CNAT, nos laboratórios de informática da diretoria. Foram reservados horários para a avaliação por turma e todo o processo foi discutido, orientado e acompanhado por, pelo menos, um dos integrantes da equipe. Tendo em vista que o processo envolvia alunos menores de idade, em formação conceitual e atitudinal, julgou-se necessário, além das explicações e orientações anteriores prestadas pela ETEP, o acompanhamento durante o preenchimento dos questionários, necessários para o êxito do que se propunha.

Na ocasião, os estudantes responderam não só ao formulário referente ao trabalho da ETEP, que estava sendo aplicado pela primeira vez, mas também a outros questionários alusivos à autoavaliação discente e à avaliação da prática dos professores do período letivo. Esses dois últimos processos vinham sendo desenvolvidos desde 2004, como parte da avaliação institucional desenvolvida no IFRN/CNAT por meio de outros instrumentos avaliativos. Conforme o projeto pedagógico da instituição (IFRN, 2012), essa avaliação envolve a análise dos cursos, dos programas, do desempenho de estudantes e de servidores, com o objetivo de assegurar o envolvimento da comunidade acadêmica, de forma contínua e sistemática, na apreciação crítica das práticas pedagógicas em relação ao que a instituição se propõe. Apesar de a avaliação da ETEP colaborar para a ampliação da avaliação institucional no IFRN e atender ao que está definido na proposta pedagógica da instituição requer a contínua ampliação desses processos avaliativos. Passa-se, então, a analisar os resultados da coleta de informações referentes ao trabalho da ETEP da DIATINF.

\section{A AVALIAÇÃO DA ETEP/DIATINF: RESULTADOS E PERSPECTIVAS}

A avaliação institucional precisa ter cunho formativo, pois, como afirma Dias Sobrinho (2008, p. 61), ela "[...] deve ser promovida como um processo de caráter essencialmente pedagógico. Não se trata apenas de conhecer o estado da arte, mas também de construir". Busca-se, então, reconhecer como a realidade está constituída, analisar a sua qualidade para, ainda segundo o autor (2008, p. 61) "[...] constituir as articulações, integrar as ações em malhas mais amplas de sentido, relacionar as estruturas internas aos sistemas alargados das comunidades acadêmicas e da sociedade". 
Essa análise deve ser empreendida para verificar se as ações dos sujeitos estão condizentes com o acordado no projeto pedagógico da instituição, apontando caminhos para se corrigir percursos e reforçando valores e práticas condizentes com o que se deseja alcançar. Empreender um processo dessa natureza implica compreender os significados da própria prática, analisar condutas à luz de princípios, identificar fragilidades e potencialidades do trabalho desenvolvido.

Com essa finalidade, após a aplicação dos questionários aos professores e estudantes, as coordenadoras pedagógicas da DIATINF geraram um relatório-síntese das respostas, utilizando as ferramentas do Google Drive. Verificaram, então, os resultados das avaliações tendo em vista repensar suas práticas profissionais, corroborando a orientação formativa em que a avaliação institucional deve se pautar. Segundo Dias Sobrinho (2008, p. 66), a avaliação, nessa perspectiva, possibilita a construção do conhecimento e da crítica, "[...] a tomada de consciência da necessidade de transformação do processo mesmo de avaliação e de seus agentes, bem como projeta o que é necessário para melhorar a instituição".

Conforme os dados coletados, 95\% dos estudantes informaram que, por comodidade, costumam procurar a Pedagoga que está em serviço no seu horário de aula, mas que é corriqueiro para 3\% buscarem a pedagoga de outro turno, por apresentarem maior afinidade com determinada profissional, muitas vezes, por entenderem que seu atendimento é mais cortês ou eficiente. Essa informação foi importante para que os membros da equipe repensassem seus perfis pessoais e posturas profissionais, tendo em vista serem mais atenciosos, receptivos e empáticos para com os alunos, pais/responsáveis e professores atendidos. Esse fato é importante, visto que esse profissional é, na maioria das vezes, o mediador dos conflitos e da relação aluno-aluno, aluno- professor, professor-pais/responsáveis, escola-pais/responsáveis. Por isso, uma boa receptividade faz com que essas pessoas confiem no serviço oferecido e construam uma visão positiva da instituição de ensino.

Além de possuir boa fundamentação teórica acerca do seu ofício, conhecimento quanto à legislação educacional, capacidade de planejamento, o desempenho da função de pedagogo do IFRN, precisa também promover um trabalho cooperativo, baseado no diálogo, objetivando a articulação entre a formação discente e docente. A diversidade, a particularidade e a subjetividade estão presentes na atuação profissional, mas o zelo com as relações interpessoais é relevante, visto que o coordenador-pedagógico deve articular as relações interpessoais em meio a uma comunidade diversa em pensamentos e ações.

Os alunos, ao responderem aos questionários aplicados, demonstraram perceber que a ETEP faz um acompanhamento de sua frequência, de seu rendimento e da avaliação do processo ensino- aprendizagem, conforme demonstram as figuras 3 e 4. 


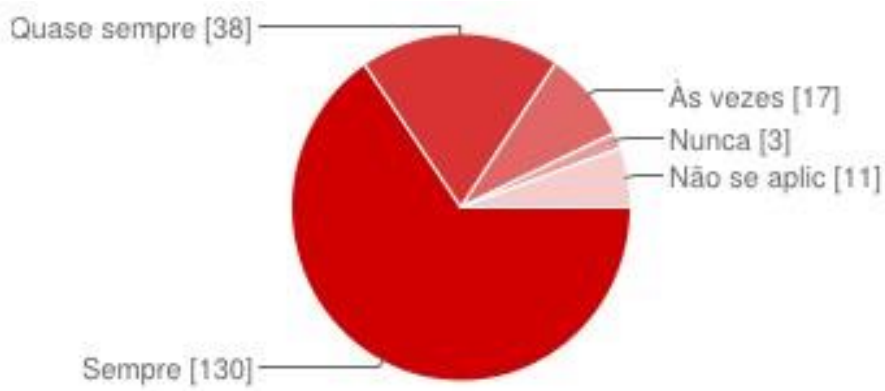

$\begin{array}{lrr}\text { Sempre } & 130 & 65 \% \\ \text { Quase sempre } & 38 & 19 \% \\ \text { Às vezes } & 17 & 9 \% \\ \text { Nunca } & 3 & 2 \% \\ \text { Não se aplica } & 11 & 6 \%\end{array}$

Figura 3: Acompanhamento da frequência e rendimento dos alunos pela ETEP/DIATINF

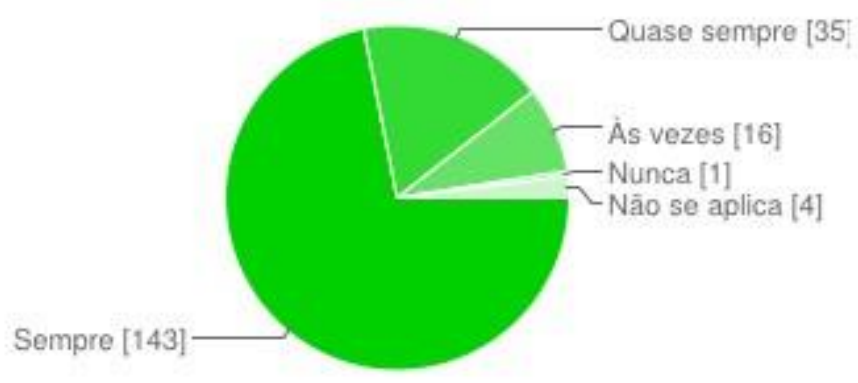

$\begin{array}{lrr}\text { Sempre } & \mathbf{1 4 3} & 72 \% \\ \text { Quase sempre } & 35 & 18 \% \\ \text { Às vezes } & \mathbf{1 6} & 8 \% \\ \text { Nunca } & \mathbf{1} & 1 \% \\ \text { Não se aplica } & \mathbf{4} & 2 \%\end{array}$

Figura 4: Avaliação conjunta (ETEP/DIATINF e Turmas) do processo de ensino-aprendizagem.

Conforme as figuras 3 e 4, $84 \%$ dos estudantes reconhecem que, sempre ou quase sempre, a ETEP acompanha sua frequência e rendimento escolar. Essa incumbência é atribuída aos estabelecimentos de ensino pela Lei de Diretrizes e Bases da Educação Nacional, Lei 9.394, de 20 de dezembro de 1996, no Art. 12 (BRASIL, 1996). No IFRN, cabe às pedagogas junto aos professores realizarem esse acompanhamento visando, ainda, desenvolver estratégias de recuperação do rendimento dos estudantes. Apesar do bom resultado obtido, alguns estudantes sinalizaram existir certo distanciamento entre a ETEP e os líderes de turma, nos últimos anos, conforme pode ser verificado na figura 5 .

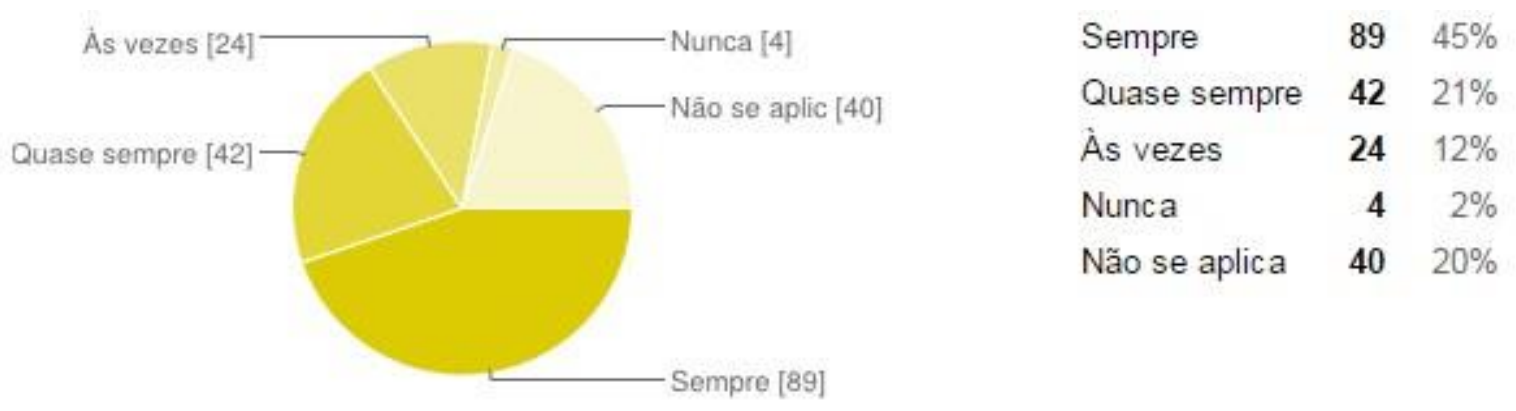

Figura 5: Realização de reuniões entre a ETEP e os representantes de turma.

Conforme a figura 5, em análise, $66 \%$ dos estudantes consideraram que a ETEP sempre ou quase sempre promovia reuniões com os representantes de turmas. Considerando os comentários descritos pelos alunos no espaço disponibilizado para esse fim, eles, porém, manifestaram a necessidade de um número mais expressivo de reuniões e de outras atividades que envolvessem os representantes de turma, conforme acontecia até 2010. Na ocasião, a ETEP 
na DIATINF possuía, apenas, uma pedagoga, o que dificultava o desenvolvimento de atividades que envolvessem todas as turmas, além de exigir um contato mais frequente com os representantes. Com a chegada de mais uma pedagoga na equipe e a identificação de que algumas informações não estavam sendo repassadas, devidamente, pelos líderes, essas atividades foram reorientadas, visando otimizar o acompanhamento dos estudantes. Desde então, foram enfatizadas atividades que envolvessem as turmas completas.

O resultado da avaliação da ETEP levou a equipe a redefinir, em 2014, as atividades desenvolvidas com os líderes de turma, com vistas a reorganizar suas atribuições. Buscou-se conferir maior responsabilidade aos representantes no trato com os seus pares, bem como promover sua participação em ações de acompanhamento da aprendizagem da sua turma no conselho de classe e outros órgãos representativos da Instituição.

Nas respostas aos questionários, os alunos indicaram que julgavam as ações da ETEP, no que se refere à mediação de conflitos, efetivas e eficientes. Quando perguntados se a equipe ajudava a solucionar conflitos e dificuldades de relacionamento professor-aluno e aluno-aluno, $43.7 \%$ responderam "sempre", e $15.6 \%$ responderam "quase sempre", totalizando quase $60 \%$ de respostas positivas nesse quesito. Os discentes comentaram, inclusive, que, em face dos encaminhamentos da Equipe, com base nos dados da avaliação das turmas, alguns professores modificaram condutas apontadas pela turma como prejudiciais ou que poderiam dificultar o processo de ensino- aprendizagem.

Identificou-se, ainda, que os alunos desconheciam, substancialmente, as ações que envolviam a escola e os seus pais/responsáveis, como, por exemplo, os atendimentos às famílias, reuniões de pais/responsáveis, plantões pedagógicos e conselhos de classe. Um número bastante significativo, quase $20 \%$ dos estudantes que responderam às questões, marcou a alternativa "não se aplica", quando questionado sobre a realização de atendimentos individualizados aos pais/responsáveis, demonstrando desconhecimento sobre o quesito questionado.

Essa informação fomentou a discussão na equipe sobre a necessidade de coletar informações diretamente com os pais. Esse fato também suscitou dúvidas sobre a razão desse desconhecimento por parte dos alunos: Os pais/responsáveis não conversam com seus filhos sobre sua vida acadêmica? Que autonomia os pais/responsáveis dão aos alunos para tomar decisões referentes às suas vidas acadêmicas? Essas questões foram tomadas como novas demandas para o trabalho da ETEP junto aos pais/responsáveis pelos alunos, visto que os atendimentos estão ocorrendo, de fato, mas as informações não são conhecidas por parte significativa dos discentes.

Com base nessas informações, a ETEP/DIATINF teve oportunidade de refletir sobre a sua prática, buscando desenvolver novas estratégias para dinamizar o trabalho pedagógico que realiza. Dessa forma, o processo de avaliação empreendido representa, para os sujeitos, "um processo de descrição, análise e crítica de uma dada realidade, visando transformá-la" (SAUL, 2006, p. 61). Pela sua abrangência e pelos desafios que se impõem para que se continue avançando rumo à melhoria das ações, a avaliação institucional interna requer do grupo de 
profissionais que decidiram implementá-la, "[...] forte vontade política e uma confiança muito grande nos efeitos positivos desse processo" (RISTOFF, 2008, p. 72).

Pode-se afirmar que, de modo geral, o trabalho da ETEP foi bem avaliado pelos estudantes, que se mostraram capazes de avaliar os quesitos requeridos, recorrendo pouco à alternativa "não se aplica" nas questões objetivas, o que poderia demonstrar desconhecimento sobre as questões abordadas. No entanto, percebe-se que a Equipe precisa ainda investir no esclarecimento quanto às suas atribuições, pois, em alguns comentários livres, os estudantes cobraram ações, principalmente, no que se refere a demandas relacionadas à Assistência Estudantil, que não integram as atribuições da ETEP, mas dos coordenadores de curso, Diretores Acadêmicos ou outros profissionais da Instituição.

Pertinente aos dados obtidos por meio da avaliação dos professores, foi possível obter a visão dos docentes sobre cada membro da ETEP, pois os formulários referiam-se à atuação de cada uma das pedagogas da DIATINF. A estagiária que, também, participava da equipe, à época, não foi avaliada porque suas atividades eram de suporte ao trabalho da ETEP. Embora o estágio tenha um cunho essencialmente formativo, esse aprendiz teve suas ações limitadas pelas atribuições previstas em contrato de atuação temporária; por isso, a avaliação das ações da estagiária foi desenvolvida, somente, pela ETEP, que supervisionou o estágio.

As figuras 6 e 7 demonstram que, apesar das especificidades inerentes a cada profissional, mais de $80 \%$ dos professores que participaram da avaliação, analisaram que ambas as pedagogas mantêm sempre uma postura profissional que atende às expectativas. $100 \%$ dos respondentes consideraram que essas pedagogas demonstram sempre ou quase sempre posturas como assiduidade, disponibilidade para atendimento e encaminhamentos das questões em prazos apropriados, o que demonstra o bom desempenho das profissionais.

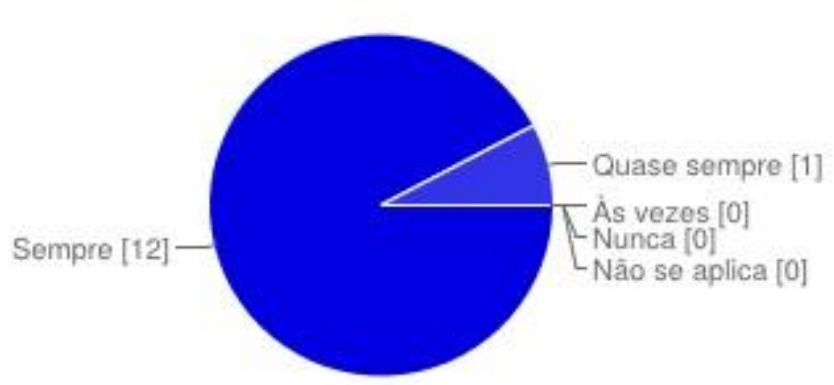

$\begin{array}{lrr}\text { Sempre } & 12 & 92 \% \\ \text { Quase sempre } & 1 & 8 \% \\ \text { Às vezes } & 0 & 0 \% \\ \text { Nunca } & 0 & 0 \% \\ \text { Não se aplica } & 0 & 0 \%\end{array}$

Figura 6: Postura profissional adequada da pedagoga $X$ da ETEP/DIATINF.

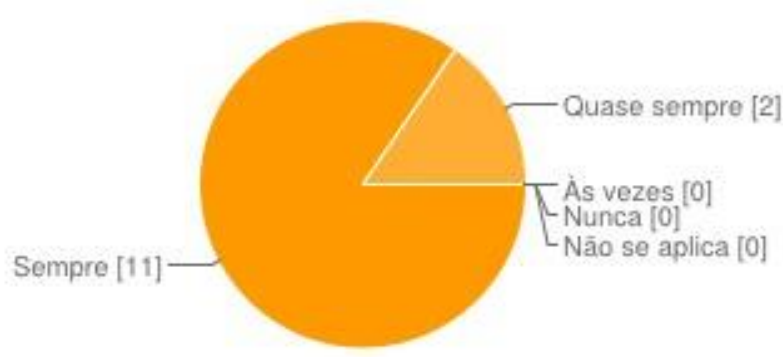

$\begin{array}{lrr}\text { Sempre } & \mathbf{1 1} & 85 \% \\ \text { Quase sempre } & \mathbf{2} & 15 \% \\ \text { Às vezes } & 0 & 0 \% \\ \text { Nunca } & 0 & 0 \% \\ \text { Não se aplica } & 0 & 0 \%\end{array}$

Figura 7: Postura profissional adequada da pedagoga $Y$ da ETEP/DIATINF. 
Além desse resultado que aborda a postura profissional de forma geral, há particularidades nas avaliações em relação a outros quesitos pesquisados. As figuras 8 e 9 referem à participação e à coordenação de reuniões de conselhos, colegiados e de pais/responsáveis realizadas pelas pedagogas.

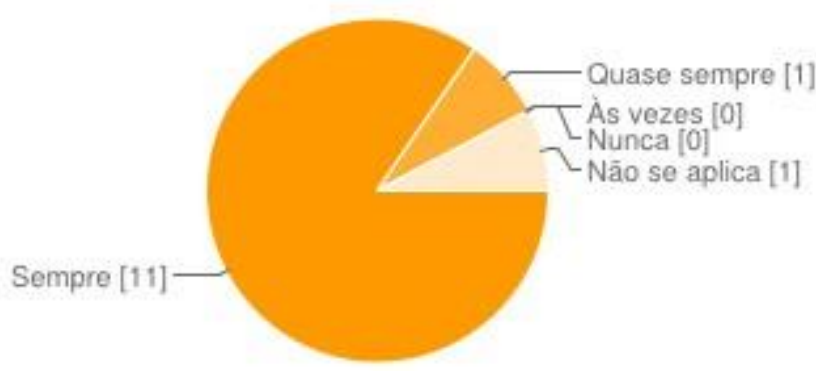

$\begin{array}{lrr}\text { Sempre } & 11 & 85 \% \\ \text { Quase sempre } & 1 & 8 \% \\ \text { Às vezes } & 0 & 0 \% \\ \text { Nunca } & 0 & 0 \% \\ \text { Não se aplica } & 1 & 8 \%\end{array}$

Figura 8: Coordenação/participação do planejamento e realização dos conselhos de classe, colegiados de cursos e reuniões de pais pela pedagoga $X$ da ETEP/DIATINF.

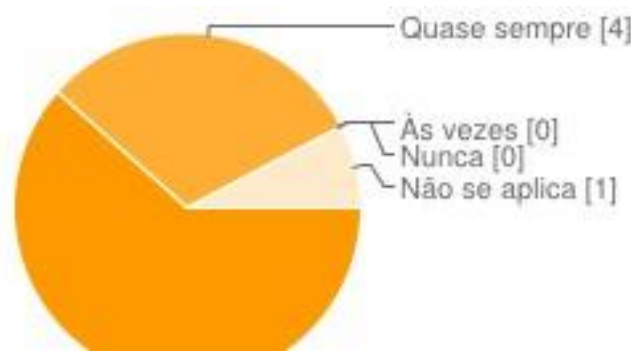

$\begin{array}{lrr}\text { Sempre } & 8 & 62 \% \\ \text { Quase sempre } & 4 & 31 \% \\ \text { Às vezes } & 0 & 0 \% \\ \text { Nunca } & 0 & 0 \% \\ \text { Não se aplica } & 1 & 8 \%\end{array}$

Figura 9: Coordenação/participação do planejamento e realização dos conselhos de classe, colegiados de cursos e reuniões de pais pela pedagoga Y da ETEP/DIATINF.

Dessa forma, 93\% dos professores consideram que as duas pedagogas sempre ou quase sempre cumprem as suas tarefas no referido requisito. Apesar disso, a atuação de uma se diferencia da outra, o que pode levar repensar condutas e futuras perspectivas de trabalho. 0 quesito em análise refere-se ao planejamento coletivo e à participação das pedagogas em instâncias colegiadas que consistem em importantes oportunidades de participação da comunidade escolar, conforme o projeto político-pedagógico da Instituição (IFRN, 2012). Segundo esse projeto (IFRN, 2012), a instituição adota a concepção crítico-dialética de gestão democrática, que pressupõe a descentralização, a participação e a autonomia dos atores sociais envolvidos. Isso requer que a equipe pedagógica se responsabilize por coordenar conselhos de classe, colegiados de cursos e reuniões de pais/responsáveis, entre outros espaços de inter-relação dos sujeitos, dos quais se espera efetiva participação.

Essa participação é essencial pelo fato de proporcionar visão abrangente do processo educativo; possibilitar a formação necessária ao exercício da cidadania; preparar os sujeitos para o mundo do trabalho; superar o individualismo tendo em vista interesses e finalidades comuns. A equipe pedagógica deve fomentar a construção de espaços destinados ao trabalho coletivo, pois, a partir da interação interpessoal, o pedagogo pode exercer uma de suas principais funções, que consiste na promoção da reflexão contínua e coletiva dos professores acerca da própria prática pedagógica. Na concepção de Arroyo (2000, apud VASCONCELLOS, 2002, p. 162), a construção do conhecimento deve ocorrer por meio da interação dos sujeitos, pois "[...] a 
prática educativa, quando refletida coletivamente, é a melhor fonte de ensinamento teórico e, sobretudo, de práticas mais comprometidas". No projeto político-pedagógico do IFRN (IFRN, 2012), reconhecem-se as reuniões pedagógicas como espaços que promovem a interação dos sujeitos com esse fim, uma vez que são

[...] espaços coletivos conquistados para a reflexão, para o planejamento e para o replanejamento da prática pedagógica institucional. Nas reuniões pedagógicas, é possível tanto favorecer a construção e a difusão dos saberes (estudos temáticos da docência e/ou outros estudos) quanto permitir a troca de experiências e a socialização de conhecimentos (IFRN 2012, p. 70).

Ainda de acordo com esse projeto (IFRN, 2012), as reuniões pedagógicas devem ser planejadas e coordenadas pela equipe técnico-pedagógica e pela Diretoria Acadêmica, com apoio da Psicologia Escolar, acontecendo, semanalmente, e com horários preestabelecidos e previamente distribuídos na carga horária dos profissionais envolvidos. Por isso, os professores foram indagados sobre a realização dessas reuniões como espaço de reflexão, (re)planejamento da prática institucional. A figura 10 , a seguir, sintetiza as respostas a esse questionamento:

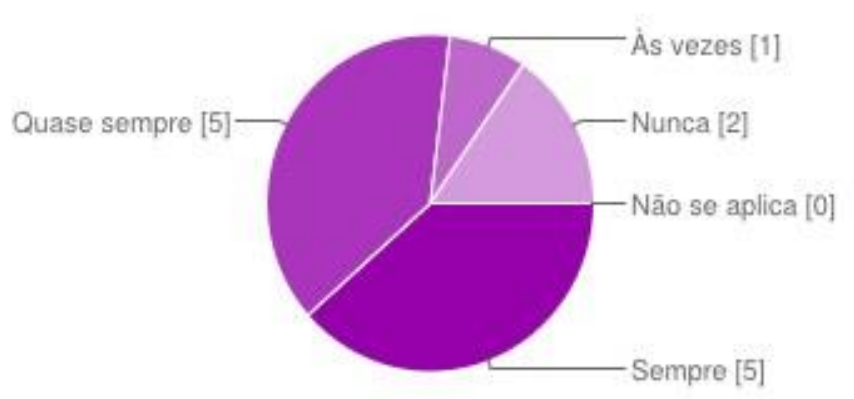

$\begin{array}{lrr}\text { Sempre } & 5 & 38 \% \\ \text { Quase sempre } & 5 & 38 \% \\ \text { Às vezes } & \mathbf{1} & 8 \% \\ \text { Nunca } & 2 & 15 \% \\ \text { Não se aplica } & 0 & 0 \%\end{array}$

Figura 10: Realização de reuniões pedagógicas como espaços coletivos para reflexão, planejamento e replanejamento da prática institucional, conforme PPP do IFRN.

Quanto ao cumprimento da função posta pelo PPP do IFRN para as reuniões pedagógicas, $23 \%$ dos professores que responderam ao questionário afirmaram que isso nunca ocorre ou acontece às vezes. Essas respostas são justificadas pelo fato de que há pouca objetividade nas discussões, caracterizadas, muitas vezes, por "desabafos" que, segundo eles, interferem no desenvolvimento da pauta proposta, dificultando, assim, os necessários encaminhamentos. Além disso, os docentes alertaram para a necessidade de focalizar as ações pedagógicas, em especial, as de formação continuada, em detrimento das pautas relacionadas às questões administrativas.

Os $76 \%$ dos docentes que consideram que sempre ou quase sempre as reuniões pedagógicas consistem em espaços de reflexão e (re)planejamento institucional comentaram que as pautas trabalhadas nas Reuniões Pedagógicas têm sido relevantes para situar o professor, orientando-o nos contextos de sua prática. Dessa forma, elas têm possibilitado a compreensão das rotinas pedagógicas e administrativas.

A ETEP/DIATINF considerou riquíssimos os dados referentes a essa questão, visto que acredita que é preciso qualificar e garantir espaços de formação continuada e em serviço, que possibilitam a ação-reflexão-ação docente sobre suas práticas pedagógicas. Alarcão (1996) 
analisa a importância das três ideias centrais da teoria da prática reflexiva de Donald Schön, para a formação de um profissional reflexivo: a reflexão-na-ação, a reflexão-sobre-a-ação e a reflexão sobre a reflexão-na-ação. A autora (1996) explica que a reflexão-na-ação ocorre quando se reflete durante a própria ação e é reformulada enquanto se está realizando-a; a reflexãosobre a-ação acontece quando se recorre a uma reconstrução mental de uma ação para analisála retrospectivamente; já a reflexão sobre a reflexão-na-ação configura um momento de reflexão que proporciona uma progressão no desenvolvimento profissional, na medida em que permite a construção de uma maneira pessoal de conhecer. Esse processo é relevante porque valoriza a problematização e o conhecimento oriundo da prática inteligente e refletida, baseada numa perspectiva construtivista, extrapolando um fazer rotineiro e automatizado.

As reuniões pedagógicas do IFRN devem se constituir em espaços privilegiados onde a reflexão sobre a reflexão-na-ação pode ocorrer de modo colaborativo pelos professores auxiliando o desempenho das funções docentes. Consiste, ainda, em ambiente colaborativo para o debate sobre questões relacionadas à pesquisa e à extensão bem como sobre o funcionamento da Instituição que legitimam a participação dos sujeitos nas tomadas de decisões. É, exatamente, nesse espaço onde os membros da equipe põem em prática o seu papel

[...] de articuladores e defensores da democracia organizacional, extensiva aos saberes e fazeres da escola como atividade intrínseca e extrínseca da qual todos são protagonistas, em respeito e compreensão das atribuições e papéis sociais a serem desenvolvidos em prol da coletividade (LIMA, 2007, p. 86).

Isso demonstra a necessidade de ouvir o professor, fazê-lo revelar o que e como pensa, como considera que determinada questão deve ser tratada. As críticas acerca da utilização do tempo das reuniões pedagógicas realizadas pelos professores respondentes embasaram o desenvolvimento de nova proposta para o ano letivo de 2014. Esta, por sua vez, propiciou o planejamento coletivo das pautas das reuniões, a socialização do planejamento, dos encaminhamentos de dados e das propostas de formação em serviço dos grupos de professores da DIATINF.

Desde então, essas discussões vêm sendo socializadas em um site de acesso restrito aos servidores da diretoria, no qual estão disponíveis os planejamentos das Reuniões Pedagógicas do semestre letivo, bem como o registro em atas das reuniões ocorridas. $O$ site proporciona aos professores e demais servidores da DIATINF um espaço para conhecimento das ações pedagógico- administrativas da diretoria bem como a possibilidade de proposição de novas pautas e demandas.

O processo de avaliação institucional, instituído pela ETEP da DIATINF, requereu e consolidou o amadurecimento das pessoas envolvidas, tanto no que se refere aos avaliadores quanto aos avaliados, no sentido do respeito ao outro, da aprendizagem coletiva e da disposição pelo fato de implementar mudanças no próprio trabalho. Esse repensar sobre as atividades cotidianas da Equipe TécnicoPedagógica, com base nos dados coletados com a avaliação, foi essencial para (re)construção de sua identidade e (re)alinhamento de suas ações com o que propõe o projeto pedagógico da instituição. 


\section{CONSIDERAÇÕES FINAIS}

A avaliação da equipe técnico-pedagógica da DIATINF/IFRN/CNAT foi, sem dúvida, mais um passo para o desenvolvimento da cultura de avaliação na instituição e do sentimento de pertencimento das pedagogas a esse processo, a partir da abertura para o exame da própria prática. O processo empreendido foi bem aceito pelos sujeitos envolvidos, considerando o caráter formativo da avaliação empreendida com vistas à reorientação das práticas pedagógicoadministrativas.

Para os avaliadores do trabalho da equipe - quer discentes ou docentes - a experiência consistiu em importante oportunidade de expressão de pensamentos e sentimentos. Dessa forma, contribuíram para que a equipe refletisse acerca das próprias atitudes e práticas, possibilitando instituir melhorias nas relações e no trabalho pedagógico que coordena.

Para a ETEP, o processo avaliativo constituiu-se em oportunidade de conhecer as próprias práticas com base em múltiplos olhares que incidiram sobre o trabalho desenvolvido. Apesar de não se tratar de um processo fácil, foi imprescindível para (re)pensar ações e consolidar práticas democráticas no interior da instituição, visando aproximar-se do referencial de qualidade e educação assumidos no projeto pedagógico da instituição.

A experiência foi bem apreciada por alguns professores, pedagogos e técnicos em assuntos educacionais de outras diretorias acadêmicas do campus Natal-Central do IFRN, que defenderam que a experiência piloto, realizada na DIATINF, fosse ampliada para todo o campus. Outro ponto importante dessa experiência foi a informatização da avaliação, que não só colaborou para ampliar o acesso aos questionários como também facilitou o trabalho de tabulação e de apresentação dos dados. Assim, para as próximas experiências avaliativas, já se planeja o desenvolvimento de um software, o Sistema de Avaliação do Processo EnsinoAprendizagem do IFRN - Campus Natal- Central (SIAPA/IFRN), cujo objetivo será otimizar ainda mais o processo de avaliação do IFRN/CNAT.

Apesar da amostra dos estudantes e professores que responderam ao questionário se adequar aos padrões estatísticos requeridos para a pesquisa, vale destacar a necessidade de sensibilização para que um maior número de pessoas responda às questões. Isso porque a experiência vivenciada consistiu em importante oportunidade para suscitar reflexões e apontar caminhos para que a comunidade escolar se aproxime do que almeja, já que não pode ficar circunscrita a um pequeno grupo.

O processo levado a efeito pela ETEP ampliou o rol dos segmentos profissionais do IFRN que teve o seu trabalho analisado visando subsidiar a própria melhoria, considerando que a avaliação institucional deve ser pensada na perspectiva da totalidade em que todos avaliam e são avaliados. Dessa forma, abre-se espaço para que se planejem melhorias e cria-se sinergia entre os sujeitos que comungam do desejo de aprender com as próprias experiências. A avaliação da ETEP foi aqui enfatizada como processo de crescimento profissional construído coletivamente, e comprova que a avaliação institucional vem ganhando espaço, credibilidade e importância no cotidiano escolar, haja vista a melhoria da qualidade educacional. 


\section{REFERÊNCIAS}

1. ALARCÃO, Isabel. Formação reflexiva de professores: estratégias de supervisão. Porto: Porto, 1996.

2. ALBERTO, Jorge Luís Moreira; BALZAN, Newton César. Avaliação de projeto políticopedagógico pelos funcionários: espaços e representatividade. Avaliação, Campinas; Sorocaba, SP, v. 13, n. 3, p. 745-770, nov. 2008.

3. BRASIL. Ministério da Educação. Encaminha a descrição dos cargos técnico-administrativos em educação, que foram autorizados pelo Ministério de Planejamento, Orçamento e Gestão para concurso público. Ofício Circular no 015/2005/CGGP/SAA/SE/MEC, de 28 de novembro de 2005.

4. DIAS SOBRINHO, José. Avaliação institucional, instrumento da qualidade educativa: a experiência da Unicamp. In: DIAS SOBRINHO, José; BALZAN, Newton César (Org.). Avaliação institucional: teoria e experiências. 4. ed. São Paulo: Cortez, 2008, p. 53-86.

5. FREITAS, Luiz Carlos et al. Avaliação educacional: caminhando pela contramão. Petrópolis: Vozes, 2009.

6. INSTITUTO FEDERAL DE EDUCAÇÃO, CIÊNCIA E TECNOLOGIA DO RIO GRANDE DO NORTE. Atribuições da equipe técnico-pedagógica no âmbito do IFRN. IV Seminário "Construindo o documento base do PPP". 20 set. 2009 (mimeo).

7. INSTITUTO FEDERAL DE EDUCAÇÃO, CIÊNCIA E TECNOLOGIA DO RIO GRANDE DO NORTE. Projeto político-pedagógico do IFRN: uma construção coletiva: documento-base. Natal: Editora da IFRN, 2012.326 p.

8. LEVIN, Jack. Estatística Aplicada a Ciências Humanas. São Paulo: Harbra, 1987.

9. LIBÂNEO, José Carlos. Avaliação de sistemas escolares e de escolas. In: LIBÂNEO, José Carlos. Organização e Gestão da Escola: teoria e prática. 4. ed. Goiânia: Alternativa, 2001, p. 199-220.

10. LIBÂNEO, José Carlos; OLIVEIRA, João Ferreira; TOSCHI, Mirza Seabra. Avaliação da educação básica. In: LIBÂNEO, José Carlos; OLIVEIRA, João Ferreira; TOSCHI, Mirza Seabra. Educação escolar: políticas, estrutura e organização. 10. ed. São Paulo: Cortez, 2012, p. 263-270.

11. LIMA, Paulo Gomes; SANTOS, Sandra Mendes dos. O coordenador pedagógico na educação básica: desafios e perspectivas. Educere et Educare, Cascavel, PR, v. 2, n. 4, p. 77-90, jul./dez. 2007.

12. RISTOFF, Dilvo I. Avaliação institucional: pensando princípios. In: DIAS SOBRINHO, José; BALZAN, Newton César (Org.). Avaliação institucional: teoria e experiências. 4. ed. São Paulo: Cortez, 2008, p. 37-51.

13. SAUL, A. M. Avaliação emancipatória: desafios à teoria e à prática de avaliação e reformulação do currículo. 7. ed. São Paulo: Cortez, 2006.

14. VASCONCELLOS, Celso dos Santos. Planejamento: projeto de ensino e aprendizagem e projeto político-pedagógico. São Paulo: Libertad, 2002. 